\title{
O ESTÁGIO CURRICULAR NO CONTEXTO DA EAD: A RELAÇÃO ENTRE TEORIA E PRÁTICA NA FORMAÇÃO DO PEDAGOGO $^{1}$
}

\author{
Ana Paula KUHN \\ Cristiano MACIEL ${ }^{\text {ii }}$
}

\begin{abstract}
RESUMO
A relação teoria e prática tem sido amplamente discutida nos cursos de Pedagogia, sendo o Estágio Curricular Supervisionado um importante elemento no processo de formação de professores. No entanto, questiona-se como se estabelece a relação teoria e prática no planejamento e efetivação do Estágio Curricular em cursos superiores, em especial, em cursos da Educação a Distância. Neste sentido, este estudo objetivou analisar como se deu a relação da teoria com a prática no processo de desenvolvimento nos três Estágios Curriculares (Educação Infantil, Ensino Fundamental e Espaços não escolares) em Pedagogia da Universidade Estadual de Mato Grosso - UNEMAT, ofertado pela Universidade Aberta do Brasil - UAB. A pesquisa foi exploratória com abordagem qualitativa, realizada com um grupo de 15 alunas. Neste grupo, realizou-se análise documental e observou-se a elaboração dos projetos de estágio, as interações presenciais e a distância, a regência em sala de aula e a análise dos relatórios reflexivos. Para este artigo, priorizou-se o relato dos relatórios reflexivos. Os resultados apontaram que a vivência do Estágio Curricular necessita potencializar o exercício da reflexão crítica acerca das práticas de ensinar e do saber docente, o que implica problematização e trocas de experiências e de conhecimentos para o trabalho coletivo e para a compreensão da escola como contexto singular de formação de professores. As análises foram realizadas considerando o Projeto do Curso de Pedagogia que corrobora a concepção de professor enquanto intelectual transformador, discutido por Giroux (1997). Pressupõe-se que o estágio curricular supervisionado tem a função fundamental que não é apenas a de levar os conhecimentos teóricos ao campo da prática, mas compreendê-los, pensando a realidade vivida pelo futuro professor.
\end{abstract}

PALAVRAS-CHAVE: Professor intelectual; Pedagogia; Teoria e prática; Estágio curricular supervisionado; Relatórios reflexivos.

THE CURRICULAR STAGE IN THE DETAILED CONTEXT: THE RELATIONSHIP BETWEEN THEORY AND PRACTICE IN THE FORMATION OF THE PEDAGOGUE

\begin{abstract}
The relation theory and practice has been widely discussed in the Pedagogy Courses, with the Supervised Curricular Internship being an important element in the Teacher Training process. The Internship is understood as one of the spaces that allows the effective knowledge and knowledge required for teaching practice. Based on this understanding, this study sought to analyze how the

\footnotetext{
${ }^{i}$ Doutora em Educação pela Universidade Federal de Mato Grosso (UFMT). Desde 2007 é Professora efetiva da Universidade do Estado de Mato Grosso (UNEMAT), na área de Metodologia. E-mail: profapaulaunemat@hotmail.com.

ii Doutor em Ciência da Computação pela Universidade Federal Fluminense (UFF), com estágio na Universidade de Coimbra, em Portugal (2008). Professor Associado II do Instituto de Computação da Universidade Federal de Mato Grosso (UFMT); professor do Programa de Pós-Graduação em Educação; Diretor Geral da Fundação de Apoio e Desenvolvimento da UFMT. E-mail: crismac@gmail.com.
} 
relationship between theory and practice in the development process in the three Curricular Stages (Early Childhood Education, Elementary Education and Non-school Spaces) of the distance Pedagogy Course of the State University of Mato Grosso/UNEMAT, offered by Universidade Aberta do Brasil / $U A B$. Throughout the research, the documentary analysis of the Pedagogical Political Project of the UNEMAT/UAB Pedagogy Course, of the regulation pertinent to the Curricular Internship, of the pedagogical practice carried out in the exercise of teaching and of the reflective reports constructed by the students in the process of initial formation was carried out. The research was carried out with a group of 15 students. The elaboration of the internship projects, the face-to-face interactions and the distance and conducting in the classroom were observed. In this article we prioritize reflective reporting. The results pointed out that the experience of the Curricular Internship needs to potentiate the exercise of critical reflection on the teaching practices and the teaching knowledge, which implies problematization and exchanges of experiences and knowledge for the collective work and for understanding the school as a singular context of teacher training. The analyzes were carried out considering the Project of the Pedagogy Course that corroborates with the thought of teacher as transforming intellectual, discussed by Giroux (1999). It is assumed that the supervised curricular stage has the fundamental function that is not only to take the theoretical knowledge to the field of practice, but to understand it, to elaborate it, thinking the reality lived by the future teacher.

KEYWORDS: Intellectual teacher; Pedagogy; Theory and practice; Supervised Curricular Internship; Reflective reporting.

\title{
LA ETAPA CURRICULAR EN EL CONTEXTO DETALLADO: LA RELACIÓN ENTRE LA TEORÍA Y LA PRÁCTICA EN LA FORMACIÓN DEL PEDAGOGO
}

\begin{abstract}
RESUMEN
La relación entre la teoría y la práctica ha sido ampliamente discutida en los cursos de pedagogía, siendo la pasantía curricular supervisada un elemento importante en el proceso de formación del profesorado. Se cuestiona cómo se establece la relación entre teoría y práctica en la planificación e implementación de la Pasantía Curricular en Pedagogía en la Universidad Estatal de Mato GrossoUNEMAT ofrecida por la Universidad Abierta de Brasil-UAB. Este estudio de doctorado tuvo como objetivo analizar cómo tuvo lugar la relación entre la teoría y la práctica, en el proceso de desarrollo en las tres etapas curriculares (educación de la primera infancia, escuela primaria y espacios no escolares). Fue una investigación exploratoria con enfoque cualitativo, realizada con un grupo de 15 estudiantes. Se observó la elaboración de los proyectos de pasantías, las interacciones cara a cara y la distancia y la conducción en el aula. En este artículo, priorizamos los informes reflexivos. Los resultados mostraron que la experiencia de la pasantía curricular necesita mejorar el ejercicio de reflexión crítica sobre las prácticas de enseñanza y el conocimiento de la enseñanza, lo que implica la problematización y el intercambio de experiencias y conocimientos para el trabajo colectivo y para entender la escuela como un contexto único de formación de profesores. Los análisis se llevaron a cabo considerando el Proyecto del Curso de Pedagogía que corrobora el pensamiento del profesor como un intelectual transformador, discutido por Giroux (1997). Se supone que la pasantía curricular supervisada tiene una función fundamental, que no es solo llevar el conocimiento teórico al campo de la práctica, sino comprenderlo, pensando en la realidad que experimenta el futuro maestro.
\end{abstract}

PALABRAS CLAVE: Profesor intelectual; Pedagogía; Teoría y práctica; Pasantía curricular supervisada; Informes reflexivos. 


\section{INTRODUÇÃO}

Inicialmente, cabe informar que este artigo traz resultados de uma pesquisa de doutoramento que se preocupou em compreender a relação estabelecida entre teoria e prática no contexto dos Estágios Curriculares Supervisionados do Curso de Pedagogia UNEMAT/UAB. O texto constrói-se no campo de estudo e de pesquisa sobre a formação de professores na modalidade a distância do curso de Pedagogia UNEMAT/UAB. Neste conjunto formativo, o estágio no curso de Pedagogia é tomado como objeto de estudo colocando-se no centro da análise a relação entre teoria e prática na formação inicial de professores.

Para sustentação teórica deste estudo, buscaram-se teóricos que compreendem a teoria e a prática como processos indissociáveis. As análises foram sustentadas na perspectiva da pedagogia crítica enfatizada na proposta do Curso de Pedagogia da UNEMAT/UAB e discutida por Henry Giroux (1997). Assim, foram constituídas a partir do que foi previamente compreendido e estabelecido como fundamentos teóricos e metodológicos do curso. Merecem destaque: Imbernóm (2014), Schon (2000), Pimenta e Lima (2004), Ghedin (2002), Tardif (2012), entre outros.

Salienta-se que as trajetórias acadêmicas e profissionais influenciaram a escolha do objeto de estudo e do locus da pesquisa. As motivações advieram das vivências construídas com as práticas na orientação do curso de Pedagogia/NEAD/UFMT (2004 a 2008) e da trajetória no grupo de estudos do Laboratório de Estudos sobre Tecnologias da Informação e Comunicação na Educação - LêTece, da Universidade Federal de Mato Grosso - UFMT, encetada a partir de pesquisas de mestrado direcionadas à Educação Distância, as quais alimentaram os anseios por compreender de forma mais significativa os espaços em que a EaD vem se consolidando.

A reconhecida expansão da EaD e da consequente demanda por cuidado e atenção próprios aos cursos de licenciatura nesta modalidade de ensino suscitou a seguinte questão de pesquisa: como se estabelece a relação teoria e prática no planejamento e na efetivação do Estágio Curricular em Pedagogia da UNEMAT/UAB?

No tocante ao objetivo geral, esta pesquisa se propôs a compreender e a analisar como se dá a relação entre teoria e prática nos Estágios Curriculares Supervisionados I, II e III, previstos no curso de Pedagogia no âmbito respectivo da Educação Infantil (90h), do Ensino Fundamental (120h) e de espaços não escolares (90h). 
A metodologia adotada se pautou na abordagem qualitativa de natureza exploratória e a coleta de dados, nas seguintes técnicas: análise documental, diário de campo, observação não participante com roteiro pré-estabelecido, análise dos relatórios reflexivos confeccionados individualmente pelas acadêmicas em formação e socialização das atividades realizadas. As análises foram realizadas com a intenção de triangular os dados coletados, ou seja, observar se o entendimento e a prática das acadêmicas em relação ao processo teoria e prática evidenciam o que foi proposto no Projeto Pedagógico do Curso de Pedagogia. Entretanto, neste texto, enfocamos as análises dos relatórios reflexivos.

A escolha do polo de Sapezal foi motivada em decorrência de dois eventos: o pioneirismo do município na oferta do curso de Pedagogia em parceria entre a UNEMAT e a $\mathrm{UAB}$ e a percepção do movimento relacionado à elaboração e à prática dos Estágios Curriculares Supervisionados no decurso do doutoramento.

Com relação à estrutura do artigo, inicialmente trazemos uma breve discussão sobre o Estágio Supervisionado no Contexto da Educação a Distância e as dimensões do estágio que deram sustentação para nossas análises. Em seguida, apresenta-se o lócus da pesquisa e o itinerário do caminho metodológico adotado para realização da coleta e da análise dos dados.

No segundo momento, discute-se a percepção dos alunos em relação ao processo de teoria e prática no contexto dos relatórios reflexivos construídos com base em cada estágio curricular realizado. Concomitantemente, foram apresentados os dados coletados com o objetivo de apontar questões relevantes apuradas durante a realização do estágio supervisionado. É importante salientar que o acompanhamento se deu desde o processo de elaboração da proposta até a realização nos espaços escolares. Por fim, foram desenvolvidas algumas considerações sobre todo o processo de pesquisa realizado e relacionadas as referências bibliográficas, apêndices e os anexos fundamentais para o entendimento do que foi observado nas práticas cotidianas.

\section{O ESTÁGIO CURRICULAR SUPERVISIONADO E SUAS DIMENSÕES NO CONTEXTO DA EDUCAÇÃO A DISTÂNCIA}

O processo de Estágio Supervisionado do Curso de Pedagogia investigado nesta pesquisa insere-se no contexto da Educação a Distância. As disciplinas que dão base para a realização desses estágios foram desenvolvidas com o auxílio dos AVAS - ambientes virtuais de aprendizagem. Objetivou-se analisar como se deu a relação teoria e prática com o auxílio 
destes espaços como possibilidade de interação entre alunos e alunos x professores. Acreditouse que essa ferramenta facilitaria a interação tutor-aluno, permitindo o acesso logo após a sua escrita e a rápida intervenção do tutor, ampliando as possibilidades de diários reflexivos.

Para Anjos (2013), é interessante destacar que o modelo de ambiente virtual de aprendizagem deve ser horizontal e permitir que emissores e receptores tenham em conjunto a capacidade de construção colaborativa do conhecimento, por meio da reflexão ou da construção de conhecimentos. Cunha (1997) explica que, quando uma pessoa relata os fatos vividos por ela mesma, percebe-se que reconstrói a trajetória percorrida dando-lhe outros significados. Desse modo, a narrativa pode ser a representação que deles faz o sujeito e, dessa forma, pode ser transformadora da própria realidade. Essa pode ser uma forma de superar a racionalidade tecnológica e atribuir competência comunicativa aos que buscam $\mathrm{EaD}$.

O objetivo dessa análise foi perceber de que forma está colocada nas entrelinhas dos textos a relação entre teoria e prática. $\mathrm{O}$ entendimento sobre formação e saber docente, que orienta o presente estudo, está pautado na ideia de que formar profissionais da educação exige o desenvolvimento de práticas de análise, de reflexão e de compreensão do que seja efetivamente atuar no contexto escolar nos dias de hoje. $\mathrm{O}$ olhar deste trabalho de pesquisa esteve pautado na concepção de professor como intelectual, discutida por Henry Giroux (1997). A escola é vista como espaço econômico, cultural e social que está atrelado às questões de poder e controle. É um espaço que representa formas de conhecimentos, práticas de linguagem, relações e valores sociais que são seleções e exclusões particulares da cultura mais ampla.

Nesse sentido, com o objetivo de pensar elementos que possam estruturar o estágio na perspectiva da pedagogia mais crítica, abordada por Giroux (1997), organizamos o pensamento e a elaboração das análises deste estudo considerando as dimensões da Figura 1, a seguir. 


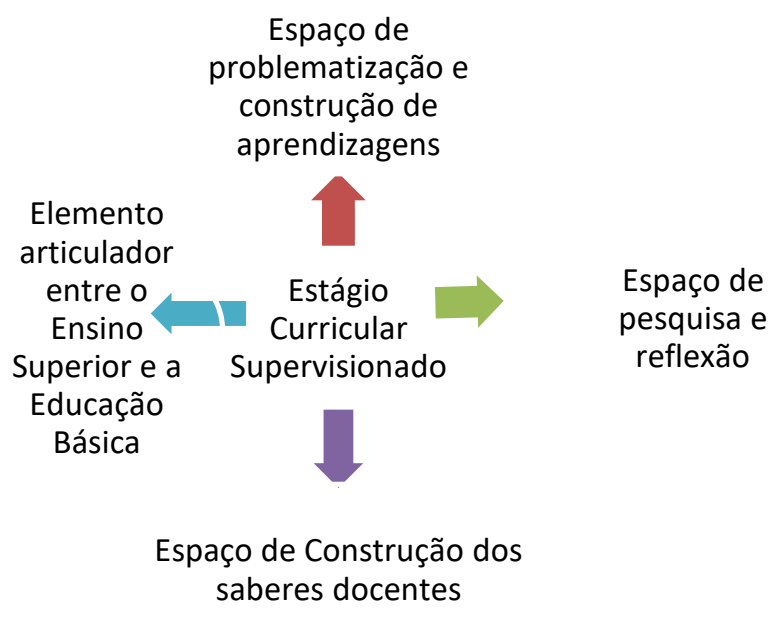

Figura 1 - Dimensões do Estágio Curricular Fonte: Dados dos autores

Foram elencadas quatro dimensões que resultaram de muitas reflexões sobre o processo de formação de professores, sobretudo no campo do Estágio Curricular. Foram articuladas a partir da compreensão crítica de professor enquanto intelectual transformador. Entende-se que essas quatro dimensões são fundamentais para a compreensão de como se deu a relação teoria e prática no desenvolvimento do Estágio Curricular do Curso de Pedagogia da UNEMAT/UAB.

O estágio, visto como espaço de problematização e construção de aprendizagens na formação de professores, precisa considerar as disciplinas e as práticas de forma articulada, mantendo uma função de complementaridade. O estágio não pode ficar sob a responsabilidade de uma única disciplina no curso de formação de professores. Ou seja, todas as disciplinas são convocadas para que, num trabalho articulado, assumam também, a partir de sua especificidade, esse processo de reflexão sobre as questões práticas, não de forma fragmentada, mas com base em uma prática interdisciplinar e coletiva (PIMENTA, 2001).

Imbernón (2014) corrobora essa discussão explicando que, se teoria e prática estiverem desarticuladas, o estágio se instala como um simples mecanismo de assimilação de conteúdos e de reprodução de exercícios práticos, vazios de significados e pautados por uma análise crítica, que não favorece a transformação.

Outro aspecto a ser considerado refere-se a assumir o estágio como elemento colaborador à avaliação de currículo, constituindo-se um espaço de pesquisa e reflexão. O curso tem a possibilidade de avaliar e corrigir a trajetória curricular a partir das reflexões vivenciadas pelos alunos no contexto escolar. Um segundo aspecto dessa dimensão diz respeito à seleção e 
organização das disciplinas do curso que, segundo Almeida (1994), deve originar-se da sala de aula, campo de trabalho dos professores que estão em formação. Isso porque é exatamente neste contexto que eles encontram as maiores dificuldades e os maiores desafios para atuarem.

Compreende-se que essas quatro dimensões do Estágio Curricular contribuem para a indissociabilidade teórico-prática. O entendimento do estágio enquanto elemento de articulação teoria-prática foi assumido como uma das funções primordiais desse componente curricular, obrigatório no processo de formação de professores. É nesse momento que os alunos têm a oportunidade de, participando da formação oferecida nas instituições formadoras, ao mesmo tempo, ter um contato mais direto com a realidade educacional das escolas. Há uma aproximação com a prática, uma vez que o tempo é limitado e os alunos não conseguem conquistar um espaço considerável de autonomia. É importante que o aluno estagiário respeite o planejamento das atividades curriculares já construídos pela escola no momento da realização dos estágios do seu Curso de Formação. O Estágio constitui-se espaço importante para a aproximação entre a Universidade e a Escola de Educação Básica.

Tais discussões nos fazem pensar o estágio enquanto espaço de construção de saberes docentes. Giroux (1997) afirma que o professor precisa reconhecer-se como sujeito capaz de fazer mudanças, pois, além de se manifestar contra as injustiças econômicas, políticas e sociais dentro e fora da escola, também busca promover condições para que os alunos se tornem mais críticos e transformadores. Entende-se que essa compreensão sobre o estágio contribui significativamente para a formação de professores intelectuais. Embora se tenha consciência de que talvez o tempo de estágio seja bastante restrito e muitas vezes apareça como elemento isolado, ao final do curso, apenas para cumprimento de carga horária.

Para Giroux (1997, p. 187), a prática de professores como intelectuais necessita:

Fornecer aos estudantes os instrumentos críticos para compreender e desmantelar a racionalização crônica de práticas sociais prejudiciais e, ao mesmo tempo, apropriar-se do conhecimento e habilidades que precisam para repensar o projeto de emancipação humana. Engajar-se ativamente em projetos que os estimulem a abordar seu próprio papel crítico na produção e legitimação das relações sociais. Tais projetos são necessários, não apenas para lutar contra os intelectuais conservadores e os múltiplos contextos nos quais os processos de legitimação ocorrem, mas também para ampliar os movimentos teóricos e políticos fora da universidade.

Nesse sentido, mais uma vez enfatiza-se que o estágio é uma importante parte integradora do currículo, em que o licenciando vai assumir a sua identidade profissional e sentir 
na pele o compromisso com o aluno, com sua família, com sua comunidade com a instituição escolar que representa sua inclusão civilizatória, com a produção conjunta de significados em sala de aula, com a democracia, com o sentido de profissionalismo que implique competência, fazer bem o que lhe compete.

\section{QUANTO AO LOCUS DA PESQUISA, ABORDAGEM E OBJETIVOS}

A pesquisa foi realizada no polo da Universidade Aberta do Brasil, no município de Sapezal, estado de Mato Grosso. Em 2016, o curso de Pedagogia a distância da UNEMAT/UAB era ministrado em sete polos: Colíder, Comodoro, Juína, Nova Xavantina, Cáceres, Campo Verde e Sapezal. Entre os sete polos, Sapezal foi o primeiro a ofertar tal curso, sendo este pioneirismo uma das razões para a escolha deste município como locus da pesquisa (com a conclusão do curso de Pedagogia a distância da Universidade Estadual de Mato Grosso, ofertado pela Universidade Aberta do Brasil em 2017, os Estágios Curriculares Supervisionados iniciaram em 2016). A opção do locus de pesquisa também foi regida por três outros aspectos: o objetivo delineado - realizar o acompanhamento de todo o processo das atividades dos estágios (o antes, o durante e o depois) - o limite do processo de doutoramento (quatro anos) e a necessidade de observação dos três estágios previstos no projeto do curso Estágio Supervisionado I (90h), Estágio Supervisionado II (120h) e Estágio Supervisionado III (90h), um requisito indispensável à consecução do objetivo da pesquisa.

O Estágio Supervisionado do Curso foi distribuído em três disciplinas intituladas, respectivamente: Estágio Supervisionado I, Estágio Supervisionado II e Estágio Supervisionado III, a serem cursadas a partir da segunda metade do Curso, totalizando uma carga horária de 300h. Essa carga horária está de acordo com a recomendação do CNE já expresso anteriormente. (UNIVERSIDADE DO ESTADO DE MATO GROSSO, 2016, p. 12)

Assim, com o espaço de investigação delimitado e com o objetivo de analisar a relação entre teoria e prática no contexto dos Estágios Curriculares Supervisionados, iniciaram-se os primeiros movimentos de coleta de dados.

O itinerário investigativo fundamentou-se nos pressupostos da pesquisa qualitativa em educação. Compreende-se que o pesquisador qualitativo pauta seus estudos na interpretação do mundo real, preocupando-se com o caráter hermenêutico na tarefa de pesquisar sobre a experiência vivida dos seres humanos. Para Minayo (2001), a pesquisa qualitativa trabalha com o universo de significados, motivos, aspirações, crenças, valores e atitudes, o que corresponde 
a um espaço mais profundo das relações, dos processos e dos fenômenos que não podem ser reduzidos à operacionalização de variáveis.

Quanto aos objetivos da pesquisa, utilizou-se de pesquisa exploratória no intuito de conhecer o ambiente pesquisado. Segundo Gil (2007), essas pesquisas têm como objetivo proporcionar o maior conhecimento possível sobre o que está sendo pesquisado, levantando inclusive hipóteses. Seu planejamento é bastante flexível, de modo a possibilitar a consideração dos mais variados aspectos relativos ao fato estudado.

Nesta pesquisa, optou-se pela triangulação dos dados. Para Yin (2010), em se tratando de estudos de caso, as fontes mais comumente utilizadas são: documentação, registro em arquivos, entrevistas, observação direta, observação participante e artefatos físicos. O método de triangulação sistemática pode ser compreendido por Flick (2009), a partir da combinação de perspectivas e de métodos de pesquisa adequados, que possam ser apropriados para levar em conta o máximo possível de aspectos distintos de um mesmo problema. Neste estudo, utilizouse de análise documental, observação não participante das regências em sala de aula e análise dos relatórios reflexivos. "É a alternativa para se empreender múltiplas práticas metodológicas, perspectivas e observadores em uma mesma pesquisa, o que garante rigor, riqueza e complexidade ao trabalho". (2006, p.19)

Realizou-se a pesquisa documental observando o PPC do Curso de Pedagogia da UNEMAT/UAB, os planos de ensino e os relatórios reflexivos construídos como finalização dos estágios curriculares. A pesquisa documental foi utilizada como fonte de coleta de dados. A riqueza de informações que deles se pode extrair possibilita ampliar o entendimento de objetos cuja compreensão necessita de contextualização histórica e sociocultural.

A pesquisa documental recorre a fontes mais diversificadas e dispersas, sem tratamento analítico, tais como: tabelas estatísticas, jornais, revistas, relatórios, documentos oficiais, cartas, filmes, fotografias, pinturas, tapeçarias, relatórios de empresas, vídeos de programas de televisão, etc. (FONSECA, 2002, p. 32).

Realizou-se a análise do projeto político-pedagógico do curso de Pedagogia UNEMAT/UAB, no intuito de compreender como os estágios foram organizados e como a proposta do curso concebe a relação entre teoria e prática.

A observação sistemática não participante ocorreu durante o exercício da elaboração dos planos de aulas, da regência em sala de aula e na "socialização das atividades 
desenvolvidas", momento que ocorreu após a realização dos três estágios, proposto e orientado pela tutora presencial do Curso. Segundo Lüdke e André (1986), a observação possibilita o contato pessoal do pesquisador com o fenômeno pesquisado, favorecendo a verificação da ocorrência de determinado objeto de estudo. Neste estudo, a observação teve por objetivo analisar como se deu a prática pedagógica dos professores em formação no exercício da docência.

É importante destacar que relatórios reflexivos foram construídos pelas acadêmicas como registros das atividades desenvolvidas durante todo o Estágio Supervisionado, foco das análises deste artigo.

\section{REFLEXÕES E ANÁlises: O PROJETO DO CURSO DE PEDAGOGIA, O PLANEJAMENTO, AS PRÁTICAS DE REGENCIA E OS RELATÓRIOS REFLEXIVOS}

Neste tópico, apresentam-se as análises que foram realizadas tomando como base o projeto político-pedagógico do curso de Pedagogia UNEMAT/UAB, os planejamentos, os registros e ações da tutoria presencial e a distância do estágio; as atividades nos polos e os relatórios reflexivos das alunas. Objetivou-se à contextualização dos cenários e análises dos dados coletados. Nas análises, foi utilizado um código alfanumérico para identificar as acadêmicas em formação que fizeram parte deste estudo: de AC01 até AC15. Todas as falas das acadêmicas em formação foram transcritas exatamente como constam nos relatórios de Estágio Curricular

Salienta-se que nosso olhar de pesquisadores teve por objetivo compreender como se estabelece a relação teoria e prática nos Estágios Curriculares do Curso de Pedagogia. Nossas reflexões ao longo deste trabalho de pesquisa estiveram pautadas na concepção de Giroux (1997) que compreende o professor como intelectual transformador. O autor afirma a necessidade de desenvolver um discurso que una a linguagem crítica à linguagem da possibilidade, trazendo maneiras de o educador se reconhecer como um agente de mudanças dentro e fora do ambiente escolar.

A seguir, apresenta-se a concepção do projeto pedagógico do curso de Pedagogia da UNEMAT/UAB. Fizemos uma discussão observando os registros nos relatórios reflexivos e a fala das acadêmicas em formação no momento da socialização. Salientamos que as anotações foram registradas no caderno de campo. 


\subsection{O Projeto Pedagógico do Curso de Pedagogia da UNEMAT/UAB: os estágios curriculares supervisionados}

Inicialmente pretende-se compreender brevemente o contexto em que o curso de Pedagogia da UNEMAT/UAB foi criado e escolhido como lócus deste estudo.

Em 2008, a UNEMAT passou a integrar o sistema Universidade Aberta do Brasil. Ligado ao MEC, pela Secretaria de Ensino a Distância, este sistema tem por prioridade a formação de educadores, por meio do estímulo à articulação e integração de uma rede nacional de educação superior. O sistema é formado por instituições de ensino superior em parcerias com estados e municípios brasileiros. Em 2010/2, a UNEMAT iniciou pela UAB a oferta dos cursos de licenciatura em Física e Ciências Biológicas e de bacharelado em Administração Pública pelo PNAP. Em 2011, foram ofertados os cursos de pós-graduação em Gestão Pública, Gestão em Saúde e Gestão Municipal, também pelo PNAP. Nesta pesquisa abordam-se especificamente os estágios do curso de Pedagogia, cujo objetivo é:

Possibilitar a formação de professores pedagogos para exercer a docência na educação infantil, na primeira fase do ensino fundamental, na modalidade Normal (ensino médio), na educação profissional na área de serviços e apoio escolar, e em outras áreas nas quais sejam previstos conhecimentos pedagógicos (UNIVERSIDADE DO ESTADO DE MATO GROSSO, 2016, p.7).

O curso de Pedagogia da UNEMAT/UAB foi estruturado em oito eixos. Os estágios curriculares estão situados no sexto eixo do curso, estando assim distribuídos:

Quadro 1 - Organização do Estágio Curricular

\begin{tabular}{|c|c|c|}
\hline $\mathbf{6}^{\mathbf{0}}$ Eixo de & Estágio Supervisionado I & $90 \mathrm{~h} / \mathrm{a}(60$ presenciais e 30 a distância $)$ \\
Estudos Estágios & Estágio Supervisionado II & $120 \mathrm{~h} / \mathrm{a}(60$ presenciais e $60 \mathrm{a}$ \\
$2016 / 2$ & Estágio Supervisionado III & $90 \mathrm{~h} / \mathrm{a}$ (45 presencia $)$ \\
& & distância $)$ \\
\hline
\end{tabular}

Fonte: Projeto Pedagógico do Curso de Pedagogia- 2016.

O projeto político-pedagógico do curso enfatiza que os momentos presenciais e a distância estarão sempre sob o acompanhamento do professor-orientador, que é responsável pela disciplina.

Percebe-se que a filosofia do Curso de Pedagogia está pautada na concepção de professor atuante, capaz de intervir e transformar a realidade que, segundo afirmações de 
Giroux (1997), apoia-se na teoria crítica, uma vez que esta, fundamentada, de um lado, na dialética do social e de outro, no particular/pessoal, atende a dimensão discursiva e crítica da consciência sobre a cultura como espaço de construção das relações de domínio político, pedagogia e poder.

Observamos os objetivos quatro e cinco do Curso de Pedagogia: "4 - Desenvolver a prática da pesquisa como forma de construção de conhecimentos; 5 - Promover a prática da interdisciplinaridade no processo de formação docente, a fim de superar a fragmentação do conhecimento (PPC, 2016, p. 06).

A disciplina Estágio Supervisionado no projeto político-pedagógico do curso tem como principal objetivo oportunizar, em momento privilegiado do exercício da prática docente, o desenvolvimento de conhecimentos, habilidades e atitudes articuladas às bases teóricas e práticas necessárias ao desenvolvimento profissional, atendendo às demandas da sociedade atual, também vivenciadas ao longo do percurso acadêmico.

Embora o curso tenha uma fundamentação teórica voltada para práticas emancipatórias, a forma como a matriz curricular do curso está construída sugere que há primeiramente uma preocupação com o cumprimento das disciplinas teóricas para tão somente depois ser feita a inserção das práticas dos estágios supervisionados. De acordo com o projeto pedagógico do curso, os princípios que fundamentam as relações teórico-práticas se desenvolvem no currículo, que é composto por um conjunto de saberes expressos pelas disciplinas e relações de aprendizagem, os quais estão imbricados em valores e atitudes político-pedagógicas que se desencadeiam no cotidiano do curso.

A proposta do Curso concebe o estágio como possibilidade de o discente atuar em várias áreas, projetar um olhar crítico e aprender a observar, problematizar e buscar soluções que acontecem nas áreas que pretende atuar. É um momento privilegiado para problematizar situações e buscar soluções para as mesmas. Pode-se concluir que a fundamentação do Projeto do Curso pressupõe a visão de Henry Giroux (1997) quando traz o conceito de professor intelectual transformador.

Assim, no próximo tópico, faremos as análises do planejamento e execução das atividades planejadas. A redação foi construída a partir das questões problematizadoras apresentadas no quadro a seguir. 
Quadro 2 - Dimensões para análise dos dados

\begin{tabular}{|c|c|}
\hline Questões problematizadoras & Aspectos a serem discutidos \\
\hline $\begin{array}{l}\text { Como se caracteriza o estágio Curricular } \\
\text { no curso de Pedagogia? }\end{array}$ & $\begin{array}{l}\text { * natureza do estágio } \\
* \text { organização e desenvolvimento do estágio na } \\
\text { Universidade e nas escolas } \\
\text { * campo de atuação dos estagiários } \\
* \text { as práticas de supervisão do estágio }\end{array}$ \\
\hline $\begin{array}{l}\text { De que forma o estágio curricular pode } \\
\text { ser importante para a formação docente? }\end{array}$ & $\begin{array}{l}\text { * instrumento de articulação teoria e prática } \\
\text { * conhecimento da realidade da escola } \\
\text { * reflexão teórica sobre a prática } \\
\text { * aprendizagem da prática do ensino }\end{array}$ \\
\hline $\begin{array}{l}\text { Quais saberes são mobilizados na } \\
\text { vivência do estágio curricular? }\end{array}$ & $\begin{array}{l}\text { * saberes da formação } \\
* \text { saberes da teoria (metodologias de ensino). }\end{array}$ \\
\hline $\begin{array}{l}\text { Que saberes são produzidos na vivência } \\
\text { do estágio supervisionado? }\end{array}$ & $\begin{array}{l}\text { * conhecimento da escola e sua organização (através da } \\
\text { observação), incluindo: } \\
\text { * conhecimento sobre os alunos } \\
\text { * conhecimento sobre as práticas de ensinar: } \\
\text { * organização e desenvolvimento das aulas/ gestão do } \\
\text { tempo (resulta da relação com os professores } \\
\text { experientes) }\end{array}$ \\
\hline
\end{tabular}

Fonte: Dados dos autores

As questões problematizadoras emergiram a partir do entendimento de que o estágio curricular é um tempo destinado a um processo de ensino e aprendizagem e como tal, as problematizações das vivências realizadas à luz da teoria, estudada nos diferentes componentes curriculares do curso, contribuem para que os professores em formação desenvolvam um processo permanente de reflexão em torno do projeto do curso, do currículo e de sua própria prática em sala de aula.

A partir desse entendimento, no próximo tópico, apresentam-se as análises dos três estágios curriculares do Curso de Pedagogia da UNEMAT/UAB com início em 2014. À medida que os dados foram sendo discutidos, procurou-se realizar a triangulação dos dados considerando o que foi observado em cada etapa da realização dos estágios curriculares.

\subsection{Sobre as práticas realizadas, os relatórios reflexivos e a socialização das atividades: a concepção das alunas sobre a relação teoria e prática}

Nos textos construídos com base nas reflexões realizadas durante o Estágio na Educação Infantil e no Ensino Fundamental, aparecem várias falas de alunas tentando evidenciar o que compreenderam da relação entre teoria e prática no contexto das vivências em sala de aula.

O olhar destinado aos relatórios reflexivos esteve pautado na compreensão de que a Proposta Pedagógica do Curso de Pedagogia apresenta este instrumento como suporte para 
realização dos Estágios Curriculares Supervisionados. Trata-se da concepção de professor intelectual transformador, explicitada por Giroux (1997).

Vejamos a fala das acadêmicas sobre a percepção que se tem sobre tal processo:

O estágio é imprescindível para fundamentação teórica e prática, os conteúdos e procedimentos metodológicos serviram para ajudar a preparar aulas diferenciadas que despertassem a curiosidade e atenção dos alunos; a cada dia, constatei o interesse cada vez maior e a interação com os assuntos abordados. Os exercícios propostos na sala de aula, as dinâmicas e atividades foram realizadas com sucesso por parte dos discentes (AC1, Relatório Reflexivo, 2017).

Na fala de AC1 acima, percebe-se uma preocupação em planejar aulas diferenciadas para os alunos, o que não se verificou em sua prática docente, uma vez que apenas reproduziu o que a professora regente havia pensado.

Já a acadêmica AC2 fala sobre a importância de se considerar as vivências já trazidas pelas crianças ao adentrarem no contexto escolar.

A importância da teoria e prática no estágio é de grande relevância, pois é só através dessa prática que entendemos o verdadeiro valor de educar, pois não é só chegar a uma sala de aula e aplicar conteúdos preestabelecidos, é observar a realidade daquele aluno ao propor as atividades, é internacionalizar uma situação para que o aluno reflita sobre ela, buscando compreender as dificuldades daquele aluno e dá tudo de si para que o aluno tenha um bom aprendizado (AC2, Relatório Reflexivo, 2017).

Percebe-se uma coerência entre a fala de AC1 e sua prática no contexto da sala de aula. A aluna trouxe atividades que valorizavam a diversidade cultural, respeitou o ritmo de aprendizagem de seus alunos, apresentou atividades que instigaram a curiosidade e que contribuíram para que os alunos pensassem.

Observa-se em demais falas a relação entre teoria e prática.

O estágio nos dá à oportunidade de testar na prática, o aprendizado teórico que temos ao longo do curso. É hora de pôr em teste, os conhecimentos pedagógicos adquiridos e refletir sobre o que e como devemos melhorar (AC1, Relatório Reflexivo, 2017).

Foi uma experiência maravilhosa o estágio, estar contextualizando a teoria com a prática buscando conhecer o aspecto social da escola, da comunidade, conhecendo os alunos em seus múltiplos aspectos, buscando dialogar-se com a prática educacional fazendo a diferença e sendo a diferença na sociedade em geral (AC3, Relatório Reflexivo, 2017). 
O estágio e a regência me proporcionaram a certeza de que é este mesmo o objetivo que busco estar em sala de aula, ensinando e aprendendo. Este processo de estágio é necessário e importante, pois tenho a oportunidade de juntar a teoria com a prática e ter a consciência do dia a dia em sala de aula. Sendo uma autoafirmação, pois vai fazendo com que eu me sinta mais segura para atuar juntamente com os alunos (AC4, Relatório Reflexivo, 2017)

A prática docente no contexto desse paradigma não seria mais a aplicação de teorias no processo de ensino, ao contrário, a teoria deriva da prática e o currículo deixa de ser racionalmente técnico. Neder (2009) explica que a práxis é uma contínua reflexão, sendo considerada uma constante forma de interação entre o conhecer (teoria) e o fazer (prática).

É importante uma análise crítica frente aos paradigmas de tradição positivista, que têm dado sustentação à maioria dos programas e projetos de formação de professores de nosso país. Um novo paradigma impõe à educação um reconhecimento da interconectividade dos problemas, que não podem mais ser compreendidos isoladamente (NEDER, 2009, p. 53).

Nesta pesquisa, observou-se que a escola foi um espaço de aplicação de atividades previamente definidas, a exemplo desta fala:

A experiência que tive durante a aplicação da intervenção na Educação Fundamental $4^{\circ}$ ano séries iniciais foi muito significativa para o melhor entendimento da teoria com a prática, tendo em vista, o planejamento das atividades. Ao elaborar meu planejamento, me senti mais segura na hora de executá-lo com as crianças, pois havia estudado e compreendido o que seria trabalhado e isto contribuiu para a compreensão de todos os alunos também. Tive que ler histórias (leitura Deleite) de forma que eles entendessem. As atividades proposta foram bem-sucedidas, a convivência com a professora e aluno foi harmoniosa e tranquila. Essa experiência foi muito significativa e me fez gostar ainda mais da educação fundamental e reforçou ainda mais a minha vontade de ser professora. Tive a oportunidade de observar a fundo e fazer parte da educação de crianças, que estão ali prontas para aprender. E ver o quanto são inteligentes a ponto de relatar do seu jeito o seu cotidiano. Diante disto sabemos que temos um papel fundamental nesse processo de ensinoaprendizagem na vida dessas crianças, e esse processo irá refletir nas séries subsequente levando um conhecimento para toda vida (AC5, Relatório Reflexivo, 2017).

Fica claro que a acadêmica "AC5" compreende que primeiro estudou a teoria para depois tentar entender isso na prática. Talvez seja a reprodução da forma de organização curricular que ainda vigora em nossos sistemas educacionais. Observa-se que, no curso investigado e na maioria dos cursos de Pedagogia, temos uma matriz curricular construída com 
uma parte de disciplinas teóricas e outra parte destinada aos momentos práticos, como se a teoria antecedesse as práticas pedagógicas.

Vejamos alguns questionamentos nesse sentido:

É possível formar-se professor em camadas superpostas e independentes de um lado, as disciplinas de conteúdo, descomprometidas com essa formação, de outro lado, as disciplinas pedagógicas, supostamente as principais responsáveis por ela? É possível dissociar o conteúdo de áreas específicas da pedagogia e didática desse conteúdo? (SOARES, 2010, p. 104).

A autora discute pressuposições que possam garantir a construção dos saberes docentes. Brzezinski (2008, p. 165) discute o que denominou de "A dimensão das habilidades didáticas". Para a autora, seria o domínio das técnicas e procedimentos metodológicos relativos à área do saber, seja no processo de aprendizagem no interior de uma sala de aula ou no processo de humanização do ser humano para a vida social.

Por que então se continua dividindo o currículo dos cursos de Pedagogia em partes teóricas e práticas? Se o entendimento construído caminha para uma indissociabilidade entre teoria e prática, as ações do curso de formação de professores necessariamente teriam de contemplar essa dimensão das habilidades didáticas apontada por Brzezinski (2008)?

Na escrita da acadêmica AC6 parece haver a compreensão de que teoria e prática são indissociáveis. "O conhecimento adquirido durante a realização do estágio supervisionado II é imprescindível para o ingresso na carreira do docente, pois é o momento onde a teoria e a prática andam de mãos dadas" (AC6, Relatório Reflexivo, 2017).

Por outro lado, isso traz a ideia de que somente no estágio curricular teoria e prática andam juntas. No trecho citado a seguir, constata-se a percepção de que teoria e prática são processos distintos que em algum momento do curso se encontram. Eis uma menção à prática do Estágio:

Conclui que a experiência vivenciada nesse estágio foi essencial, necessária, enriquecedora e muito significativa, pois me possibilitou observar e também por em prática a teoria estudada dentro do contexto escolar, contribuindo assim para uma formação contínua. Nessa prática trabalhei com base no desenvolvimento integral da criança para que se tornem cidadãos críticos, reflexivos, participativos e conscientes na sociedade onde estão inseridos. Através desse Estágio Supervisionado é que pude viver de fato a realidade escolar, possibilitando assim conhecer e ter uma real noção da rotina de uma escola, onde observei e analisei o trabalho desenvolvido, focando também na necessidade de reforçar a parceria da família e da sociedade no âmbito escolar. Ser professor e mediador de ensino aprendizagem é uma responsabilidade 
muito grande, pois devemos estar em constante buscar de conhecimento, sempre inovando as ideias e aprimorando o saber para aplicar esses valores dentro e fora do ambiente escolar, sempre respeitando as especificidades de cada um (AC7, Relatório Reflexivo, 2017).

Aqui transparece o entendimento de que primeiro se aprende uma teoria para depois colocá-la em prática, é a ideia de que toda prática nasce de uma teoria. Pimenta (1996) explica que a formação inicial não está dando conta de captar as contradições no contexto da prática social de educar, uma vez que foi desenvolvido um currículo formal com conteúdos e atividades de estágios distanciados da realidade das escolas. Percebe-se que essa organização pouco tem contribuído para criar uma nova identidade do profissional docente.

[...] Os saberes teóricos propositivos se articulam, pois, aos saberes da prática, ao mesmo tempo ressignificando-os e sendo por eles ressignificados. O papel da teoria é oferecer aos professores perspectivas de análises para compreender os contextos históricos, sociais, culturais, organizacionais, e de si mesmos como profissionais, nos quais se dá sua atividade docente, para neles intervir, transformando-os. Daí é fundamental o permanente exercício da crítica das condições materiais nas quais o ensino ocorre (PIMENTA, 2005, p. 26).

É neste contexto que as pesquisas sobre a prática pedagógica sinalizam novas perspectivas. A busca é pela reflexão sobre a necessidade do domínio e também da interação entre estes saberes para o desenvolvimento de uma prática pedagógica autônoma e emancipatória.

Segundo Medeiros e Cabral (2006), a abordagem sócio-histórica apresenta-se como a mais apropriada para desenvolver as bases de uma sociedade democrática, porque parte do princípio de que a educação é social e historicamente construída pelo homem. Assim sendo, as possibilidades de reflexão e crítica sobre as práticas docentes surgem com maior consistência.

O estágio é um processo muito importante para nós futuros professores visto que ele dá os subsídios para assimilar tanto a teoria quanto a prática, e nos possibilita como profissionais a conhecer melhor a escola, o aluno, bem como os funcionários e toda rotina de uma escola e com isso, teremos a oportunidade de colocar em prática o que observamos e aprendemos durante o estágio de observação. Desse modo, se preparar para exercer a profissão, pois esse é o desejo de mostrar o que aprendemos, pois através das práticas adquiridas durante $o$ estágio que nos possibilita a oportunidade de crescer profissionalmente. Pensando assim, procurei desenvolver os planos de aula numa perspectiva que visa proporcionar ao aluno a possibilidade de sua participação nas atividades na sala de aula, onde ele seja capaz questionar, analisar, e argumentar logicamente, com as suas experiências cotidianas e ao mesmo tempo, em realidades diferentes, logo a prática da docência é uma 
realidade na vida daqueles que querem exercer a nobre missão de ensinar (AC8, Relatório Reflexivo, 2017).

Posso dizer que o Estágio Supervisionado foi de muita relevância em minha vida profissional, adquiri muitos conhecimentos com a prática versus teoria, obtive uma visão do que é aprendido no curso de Pedagogia e no cotidiano de uma sala de aula, e percebi que há muita diferença entre prática e teoria, pois nem sempre é possível adotar todas as teorias, o professor precisa usar de estratégias em determinados momentos. Segundo Freire, nos diz que uma das qualidades à autoridade é a generosidade, para termos autoridade não precisamos ser mesquinhos e malvados, é preciso haver um clima de respeito entre professor e aluno, se respeito à liberdade do aluno, se reconheço a sua dificuldade e faço tudo por este aluno logicamente ele me terá respeito (AC9, Relatório Reflexivo, 2017).

Aqui aparece a ideia de que nem toda teoria pode ser colocada em prática. Novamente, a percepção de que são processos distintos. "O período de regência oportunizou um grande aprendizado para minha formação, entendendo os processos de ensino/aprendizagem no ensino fundamental, vivenciando na prática o que estudamos na teoria” (AC10).

Foi uma experiência maravilhosa o estágio, estar contextualizando a teoria com a prática buscando conhecer o aspecto social da escola, da comunidade, conhecendo os alunos em seus múltiplos aspectos, buscando dialogar-se com a prática educacional fazendo a diferença e sendo a diferença na sociedade em geral (AC11, Relatório Reflexivo, 2017).

Percebi durante o processo, o quanto as formas e práticas pedagógicas precisam estar atualizadas, porque presenciamos grandes mudanças no nosso mundo, e as nossas crianças estão sempre cheias de informação, é importante transmitir para elas a necessidade de seleção dessas informações, que são trazidas para sala de aula, quase sempre pelas tecnologias. Precisamos nos preparar para desenvolver de forma eficaz a nossa função de promover conhecimento, de forma interativa, prazerosa e amorosa (AC12, Relatório Reflexivo, 2017).

O estágio não é posto como a única extensão prática do currículo, ao contrário, defende-se a ideia de que a inclusão teoria-prática deve permear o currículo inteiro, como um eixo norteador das várias disciplinas. Nesta visão, o estágio é realizado como uma atividade teórico-prática, que ainda não pode ser considerada a ação profissional do professor, pois se trata de uma parte do processo de formação inicial dos acadêmicos, embora seja realizado em condições sólidas de trabalho (AC13, Relatório Reflexivo, 2017).

Quando estudamos as teorias, não temos ideia do que é a prática, estar frente a uma classe e ser o responsável pela mediação do conhecimento aos alunos. A experiência em sala de aula tanto observando quanto regendo são imprescindíveis a formação do professor, onde todas as etapas do estágio foram de suma importância e enriquecedoras para o aprendizado (AC14, Relatório Reflexivo, 2017). 
Ao analisar as falas das quatro acadêmicas acima, é fundamental pensarmos sobre as contribuições de Zeichner (1993) e Elliott (1993). É possível transportar-se para outra dimensão de igual importância, que se encontra no ápice das práticas pedagógicas e também na formação docente, sobre a qual Fiorentini, Sousa Jr. e Melo (2003, p.311) se expressam muito bem, ao dizerem que [...] "o problema do distanciamento e estranhamente entre os saberes científicos, praticados/produzidos pela academia, e aqueles praticados/produzidos pelo professor na prática docente, parece residir no modo como os professores e os acadêmicos mantêm relação com esses saberes".

Como dizem Giroux e McLaren (1995, p. 149), [...] "a voz do professor reflete os valores, as ideologias e os princípios estruturais que dão sentido às histórias, à cultura e às subjetividades que definem o trabalho do dia a dia dos educadores".

Segundo estes autores, essa relação, na maioria das vezes, decorre de uma cultura profissional marcada, ou pela racionalidade técnica que supervaloriza o conhecimento teórico, ou pelo pragmatismo praticista ou ativista que exclui a formação e a reflexão teórica e filosófica.

\section{CONSIDERAÇÕES FINAIS}

Ao longo do texto, procederam-se/ realizaram-se entrelaces reflexivos sobre a relação entre teoria e prática nos estágios curriculares supervisionados, considerando uma etapa importante do processo de formação inicial. Buscou-se compreender como o fazer pedagógico pode ter significado e ser ressignificado pela reflexão teórica e acadêmica, fato que implica um fazer com princípios e fundamentos que dão sentido à práxis pedagógica do professor.

A pesquisa permitiu-nos um olhar sobre todo o processo de desenvolvimento dos estágios, desde a elaboração dos planejamentos, regência em sala de aula, até a construção dos relatórios reflexivos e a socialização das atividades desenvolvidas pelas acadêmicas em formação. Gostaríamos de salientar inicialmente que foi um processo bastante enriquecedor enquanto pesquisadores e professores envolvidos com o Ensino Superior e comprometidos com a qualidade da educação a distância. A Educação a distância tem se mostrado como uma possibilidade para muitas pessoas por permitir que os estudantes organizem seu horário de estudo.

Ao analisar o Projeto do Curso de Pedagogia UNEMAT/UAB observa-se que, ao abordar em sua redação as finalidades da formação do Pedagogo, exprime uma preocupação e um compromisso com a competência pedagógica. O projeto prevê que os alunos consigam ter 
uma formação articulada com a realidade social, econômica e cultural. Ainda estabelece que esse pedagogo finalize o curso desenvolvendo algumas capacidades como ser um professor pesquisador, capaz de refletir, intervir e transformar a realidade educacional. É exatamente o que aprendemos com Giroux (1997), quando afirma que cabe ao professor analisar como a produção é organizada dentro das relações de poder assimétricas presentes na escola, como o currículo e as práticas pedagógicas.

Nossas anotações no caderno de campo ao longo de todo desenvolvimento dos estágios permitiram observar que o momento de construir planejamentos para realizar as intervenções em sala de aula é complexo do ponto de vista da segurança teórica que as acadêmicas em formação demonstraram. A primeira revelação da maioria delas evidenciou elementos como o medo e a insegurança em assumir a regência de uma sala de aula. Observou-se que as práticas desenvolvidas seguiram o "modelo" que foi observado nas aulas das professoras titulares das salas de aula, no período que antecede a regência. Corroboramos, neste aspecto, o pensamento de Ghedin (2002), que nos chamou a atenção para o fato de que a experiência docente é espaço gerador e produtor de conhecimento, mas que isso só é possível se houver uma sistematização que permita uma postura crítica do professor sobre suas próprias experiências.

Com base nesse entendimento, acredita-se que refletir sobre os conteúdos trabalhados, as maneiras como se trabalha, a postura frente aos educandos e ao sistema social, político, econômico e cultural é fundamental para se chegar a um saber fundado na experiência. Essa compreensão ainda está um tanto distante da realidade investigada. O Curso procura realizar algumas tentativas tímidas no que tange às reflexões que visam mudanças de posturas. As acadêmicas em formação não demonstraram autonomia na construção de seus projetos de intervenção e planos de aulas. Parece-nos compreensível, uma vez que assumiram turmas de outros professores, em um tempo pontual de realização do estágio e foram orientadas a seguir o planejamento já estabelecido pela escola.

Reportando-nos a Giroux (1997), concordamos que é chegado o momento de uma nova conceituação e compreensão da educação, na qual sejam repensadas as alternativas democráticas e fomentados novos ideais de emancipação. A partir das reflexões de Giroux e das análises realizadas nesta pesquisa, somos instigados a buscar uma nova compreensão política, teórica e crítica da natureza da dominação e do tipo de oposição que ela engendra, além da necessidade de se criar novas relações sociais e espaços públicos que incorporem formas alternativas de luta e experiência. Dessa forma, entende-se que os saberes constituídos na 
experiência e na formação profissional, mobilizados no período de estágio, são o fundamento e a essência da identidade profissional. Assim, a teoria só adquire significado quando vinculada a uma problemática originada da prática e esta pode ser transformada quando compreendida nas suas múltiplas determinações.

O Estágio Supervisionado aqui discutido no contexto da Educação a Distância necessita ser pensado e discutido como uma oportunidade imprescindível da formação de professores, momento em que é possível estabelecer uma estreita relação entre os conceitos discutidos na academia e as vivências nas práticas pedagógicas em sala de aula.

Fiorentini (2008) contribui com nosso entendimento quando afirma que pesquisas sobre o estágio indicam que, se quisermos formar professores capazes de produzir e avançar nos conhecimentos curriculares e de transformar a prática e a cultura escolar, é preciso que eles adquiram uma formação inicial que lhes proporcione uma sólida base teórico-científica relativa ao seu campo de atuação, que deve ser desenvolvida e apoiada na reflexão e na investigação sobre a prática e iniciação à docência.

Os registros contidos nos relatórios reflexivos das acadêmicas em formação evidenciaram a separação entre teoria e prática. Inúmeros foram os momentos em que as alunas disseram que estavam vivenciando na prática o que haviam apreendido nas aulas teóricas no início do Curso. Ao analisar o Projeto do Curso de Pedagogia identificamos que, embora tenha toda a fundamentação sustentada nos princípios da pedagogia crítica, a matriz curricular separa o curso em dois grandes blocos. Os eixos pertencentes ao primeiro bloco são apenas disciplinas teóricas e os eixos destinados ao segundo bloco englobam as práticas curriculares e os estágios supervisionados. Percebe-se que a fala das acadêmicas reproduz o que vivenciaram em seus processos de formação inicial, ou seja, de que inicialmente é necessário compreender as teorias para num segundo momento, colocá-las em prática.

Acredita-se que se faz necessário mais investimento na formação docente e no desenvolvimento profissional do professor. A formação docente, tanto a inicial quanto a contínua, precisa ser consistente, crítica e reflexiva e capaz de fornecer os aportes teóricos e práticos para o desenvolvimento das capacidades intelectuais do professor, direcionando-o ao seu fazer pedagógico.

É pertinente acreditar, portanto, que uma formação reflexiva poderá dar conta da superação dicotômica entre teoria e prática, ranço da racionalidade técnica. E, se esta for orientada pelos princípios da abordagem sócio-histórica, é possível que ocorra a superação das 
dificuldades e novas possibilidades sejam criadas. A abordagem sócio-histórica apresenta-se como a mais apropriada para desenvolver as bases de uma sociedade democrática, porque parte do princípio de que a educação é social e historicamente construída pelo homem.

Acreditamos nas possibilidades de reflexão e crítica sobre as práticas docentes não só nos estágios curriculares, mas durante todo o processo de formação. A transformação da escola, ao exigir a reflexão teórico-prática, necessita estar respaldada em um referencial teórico que oriente a formação docente e a intervenção na realidade, de modo a garantir a função social da escola. Acredita-se que somente o profissional crítico-reflexivo é capaz de desenvolver a práxis necessária na educação e na sociedade.

\section{REFERÊNCIAS}

ALMEIDA, Jane Soares. Estágio Supervisionado em prática de ensino: relevância para a formação ou mera atividade curricular? Revista ANDE, v.13, n. 20, p.39-42, 1994.

\section{ALMEIDA, Maria I.; PIMENTA, Selma G. Estágios supervisionados na formação docente. São Paulo: Cortez, 2014.}

ANJOS, Alexandre Martins. Tecnologias da Informação e da Comunicação, aprendizado eletrônico e ambientes virtuais de aprendizagem. In: MACIEL, Cristiano (Org.). Educação a Distância: Ambientes Virtuais de Aprendizagem. Cuiabá: EdUFMT, 2013. p. 11-58.

ARROYO, Miguel G. Ofício de mestre: imagens e autoimagens. Petrópolis, RJ: Vozes, 2000 .

BRZEZINSKI, Iría. LDB/1996: uma década de perspectivas e perplexidades na formação de profissionais da educação. In: BRZEZINSKI, Iría (Org.). LDB dez anos depois: reinterpretação sob diversos olhares. São Paulo: Cortez, 2008. p. 167-194.

CUNHA, Maria Isabel da. Conta-me agora!: As narrativas como alternativas pedagógicas na pesquisa e no ensino. Rev. Fac. Educ. v. 23, n. 1-2, jan. 1997. Disponível em:

https://www.scielo.br/scielo.php?script=sci_arttext\&pid=S0102-25551997000100010. Acesso em: 10 abr. 2020.

\section{ELLIOTT, John. La investigación-acción en educación. Madrid: Morata, 1998.}

FIORENTINI, Dario. A pesquisa e as práticas de formação de professores de matemática em face das políticas públicas no Brasil. Bolema, Rio Claro: UNESP, ano 21, n. 29, 2008, p. 4370. Disponível em:

http://www.periodicos.rc.biblioteca.unesp.br/index.php/bolema/article/view/1718/. Acesso em: 10 abr. 2020. 
PEREIRA, Elizabete M. de A. (Org.). Cartografia do trabalho docente: professor (a) pesquisador (a). 3. ed. Campinas (SP): Mercado de Letras, 2003.

FLICK, Uwe. Introdução à pesquisa qualitativa. 3. ed. Porto Alegre: Artmed, 2009.

FONSECA, João José Saraiva da. Metodologia da pesquisa científica. Ceará: Universidade Estadual do Ceará, 2002.

GHEDIN, Evandro. Professor reflexivo: da alienação da técnica à autonomia da crítica. In: PIMENTA, Selma Garrido; GHEDIN, Evandro (Orgs.). Professor reflexivo no Brasil: gênese e crítica de um conceito. São Paulo: Cortez, 2002. p. 129-150.

GIL, Antonio Carlos. Como elaborar projetos de pesquisa. 4. ed. São Paulo: Atlas, 2007.

GIROUX, Henry. A. Teoria crítica e resistência em educação: para além das teorias de reprodução. Petrópolis (RJ): Vozes, 1986.

GIROUX, Henry. A. Os professores como intelectuais: rumo a uma pedagogia crítica da aprendizagem. Porto Alegre: Artes Médicas, 1997.

GIROUX, Henry. A.; MCLAREN, Peter. Por uma pedagogia crítica da representação. Petrópolis: Vozes, 1995.

GHEDIN, Evandro. Professor reflexivo: da alienação da técnica à autonomia da crítica. In: PIMENTA, Selma. Garrido.; GHEDIN, Evandro. (Orgs.). Professor reflexivo no Brasil: gênese e crítica de um conceito. São Paulo: Cortez, 2010. p. 129-150.

IMBERNÓN, Francisco. Formação docente e profissional: formar-se para a mudança e a incerteza. São Paulo: Cortez, 2014.

LÜDKE, Menga e ANDRÉ, Marli E. D. A. Pesquisa em educação: abordagens qualitativas. São Paulo: EPU, 1986.

MCLAREN, Peter. A vida nas escolas. Uma introdução á pedagogia crítica nos fundamentos da educação. 2ed. Porto Alegre: Artes Médicas, 1997.

MEDEIROS, Marinalva Veras; CABRAL, Carmen Lúcia de Oliveira. Formação Docente: da teoria à prática em uma abordagem sócio-histórica. Revista E-curriculum. ISSN 1809-3876, São Paulo, v.1, n.2, junho de 2006. Disponível em: http://www.pucsp.br/ecurriculum. Acesso em: 20 ago. 2018.

MINAYO, Maria Cecília de Souza (Org.). (2001). Pesquisa social: teoria, método e criatividade. Rio de Janeiro: Vozes.

PIMENTA, Selma Garrido. A Didática como mediação na construção da identidade do professor uma experiência de ensino e pesquisa na Licenciatura. In: OLIVEIRA, Mariangela 
Rios \& ANDRE, Mário (Orgs.). Alternativas ao ensino de didática. Campinas: Papirus, 1996. p. 48-67.

PIMENTA, Selma Garrido; GHEDIN, Evandro (Orgs.). Professor reflexivo no Brasil: Gênese e crítica de um conceito. São Paulo: Cortez, 2002.

PIMENTA, Selma Garrido; LIMA, Maria Socorro Lucena. Estágio e docência. 4. ed. São Paulo: Cortez, 2009.

SCHÖN, Donald A. Educando o profissional reflexivo: um novo design para o ensino e a aprendizagem. Porto Alegre: Artes Médicas Sul, 2000.

TARDIF, Maurice. Saberes Docentes e Formação Profissional. 13. ed. Petrópolis, RJ: Vozes, 2012.

UNIVERSIDADE DO ESTADO DE MATO GROSSO (UNEMAT/UAB). Projeto políticopedagógico do curso de Pedagogia. Cáceres, MT. 2016.

YIN, Robert. K. Estudo de caso: planejamento e métodos. 4. ed. Porto Alegre: Bookman, 2010.

ZEICHNER, Kenneth. M. A formação reflexiva de professores: ideias e práticas. Lisboa: Educa, 1993.

\section{NOTA}

${ }^{1}$ Agradecemos à professora Dra. Kátia Morosov Alonso, do Instituto de Educação da UFMT, pelas valiosas contribuições ao longo do percurso de doutoramento. Ela esteve sempre conosco, partilhando conhecimentos e construindo saberes.

Recebido em: 15/04/2020

Aprovado em: 31/05/2020 